\section{ANÁLISIS DEL DISCURSO, LITERATURA Y CIENCIA}

\author{
Dominique Maingueneau \\ Université Paris-Sorbonne \\ ORCID iD: https://orcid.org/0000-0001-8907-218X \\ dominique.maingueneau@paris-sorbonne.fr
}

Cómo citar este artículo/Citation: Maingueneau, D. (2018). Análisis del discurso, literatura y ciencia. Arbor, 194 (790): a484. https://doi.org/10.3989/arbor.2018.790n4009

Recibido: 25 marzo 2015. Aceptado: 25 agosto 2017.

RESUMEN: Este artículo intenta presentar las características mayores del análisis del discurso literario, que se ha desarrollado desde hace una veintena de años en el interior del campo del análisis del discurso. Comienza situando el análisis del discurso literario en relación con la estilística tradicional, para subrayar que un análisis centrado sobre la noción de discurso subvierte la oposición entre texto y contexto, y por tanto entre aproximaciones internas y externas a los textos literarios. En un segundo momento, muestra que la aparición del análisis del discurso literario modifica la configuración de los estudios literarios, los cuales mantienen por naturaleza una relación ambigua con las ciencias humanas y sociales. Todo invita a distinguir dos paradigmas en el estudio de la literatura: un paradigma hermenéutico que se centra en la relación entre ciertas obras privilegiadas y sus intérpretes, y un paradigma discursivo que aprehende el discurso literario como una red de prácticas históricamente situadas.

PALABRAS CLAVE: Análisis del discurso; literatura; institución discursiva; estudios literarios; paradigma hermenéutico; paradigma discursivo.

\section{DISCOURSE ANALYSIS, LITERATURE AND SCIENCE}

Copyright: (c) 2018 CSIC. Este es un artículo de acceso abierto distribuido bajo los términos de la licencia de uso y distribución Creative Commons Reconocimiento 4.0 Internacional (CC BY 4.0).

ABSTRACT: This article aims at presenting the main characteristics of Literary Discourse Analysis, which arose in the 1990s in the huge field of discourse analysis. It starts by situating Literary Discourse Analysis in relation to traditional stylistics, in order to emphasize that an approach focused on the notion of discourse challenges the very opposition between text and context, between internal and external approaches to literary texts. Secondly, it demonstrates that the emergence of Literary Discourse Analysis modifies the configuration of literary studies, which by their very nature maintain an ambiguous relationship with Human and Social Sciences. A distinction must therefore be drawn between two paradigms in the study of literature: a hermeneutic paradigm, based on a personal relationship between outstanding works and interpreters, and a discursive paradigm, which tackles literary discourse as a network of historically and socially situated practices.

KEYWORDS: Discourse analysis; literature; discursive institution; literary studies; hermeneutic paradigm; discursive paradigm. 
La aproximación a la literatura que voy a describir aquí, el análisis del discurso literario, es reciente: en efecto, no ha emergido hasta la década de los noventa del siglo XX, en el interior del análisis del discurso, que por su parte se desarrolló desde finales de los sesenta. Comenzaré situando el análisis del discurso respecto de la estilística tradicional antes de presentar algunas de sus características. Procuraré reflexionar, en particular, sobre la manera en la que aquel puede ocupar un lugar en los estudios literarios, unos estudios que parecen sometidos a tensiones contradictorias cuando se esfuerzan por definir sus vínculos con las ciencias humanas y sociales ${ }^{1}$.

\section{DE LA ESTILÍSTICA AL ANÁLISIS DEL DISCURSO}

El análisis del discurso literario puede ser comprendido como una tentativa para superar los límites de la estilística, que tomó la sucesión de la retórica en la segunda mitad del siglo XIX. Hasta los años sesenta del siglo XX, las relaciones entre lingüística y literatura se orientaban principalmente en dos sentidos: filología y estilística. Cuando había que "establecer" un texto literario desde una perspectiva filológica se recurría a los conocimientos acumulados por la gramática histórica, a la que la literatura proporcionaba además buena parte de los datos sobre los que trabajaban los lingüistas. La estilística, por su parte, permitía articular el estudio de los hechos de lengua y la interpretación de las obras literarias. Se pueden distinguir, con mayor rigor, dos grandes tipos de estilística:

1) Una estilística escolar que, prolongando la retórica clásica, se afanaba por escrutar los "procedimientos" mediante los cuales un autor llega a crear cierto "efecto" sobre su lector. Era una estilística atomista, que consideraba el texto como el resultado de una buena utilización de la lengua por parte del autor. En la caja de herramientas del profesional de la estilística se encontraban, en lo esencial, las categorías de la gramática descriptiva usual (epíteto, nombre, construcción pasiva, elipse, etc.), y de la retórica de las figuras (metonimia, antonomasia, apóstrofe, etc.).

2) Una estilística a la que caracterizaré como "orgánica", estrechamente ligada a la estética romántica. Mucho menos practicada que la precedente pero más prestigiosa, solo ha alcanzado a la enseñanza universitaria. En ella se concebía la obra literaria como la "expresión" de la conciencia de un sujeto, el creador, el cual manifestaba a través de su obra la "visión del mundo" que le es propia. Con esta estilística puede asociarse el nombre de Leo
Spitzer, quien prolonga la concepción del estilo defendida por Proust: "El estilo no es un asunto de técnica, sino de visión" (1989, p. 474). De hecho, la estilística orgánica no enlaza exclusivamente con la lingüística, pues para ella la noción de estilo tampoco se reduce a cierto manejo de la lengua. Es así como, según el propio Spitzer, "la sangre de la creación poética es en todas partes la misma, ya la tomemos de la fuente lenguaje o ideas o intriga o composición [...] Porque era lingüista, me situé en la perspectiva de la lingüística, para avanzar hacia la unidad de la obra" (1948, p. 18). Dicha estilística contempla en efecto la obra como una proyección de los esquemas que obsesionan a una conciencia creadora: cualquiera de los niveles del texto puede ser puesto directamente en relación con ella, con ese "sol" -la metáfora es del propio Spitzer-.

Las dos estilísticas anteriores no mantienen de ningún modo una misma relación con el valor. Para la estilística que hemos Ilamado atomista un procedimiento resulta más o menos exitoso según su adecuación a la finalidad que se le atribuye. En cambio, para la estilística orgánica cada obra define sus propias normas de manera soberana.

Buena parte de la "Nueva crítica" de los años sesenta rompió con esta configuración al conferir un papel de primer orden a la lingüística. Prolongando los esfuerzos de los formalistas rusos de principios del siglo XX, la Nueva crítica intentaba apoyarse sobre los progresos de la lingüística estructural para proponer una verdadera ciencia del texto literario. En realidad, tal programa de investigación no arrojó los resultados esperados: si se entiende por "lingüística" una disciplina que objetiva las propiedades de las lenguas naturales, se observa claramente que los trabajos literarios estructuralistas no tratan de grupos nominales, de determinación, de aspecto, de tematización, etc.; ni siquiera de dialecto, de variación, de entonación, etc. Lo que en ellos se manipula fundamentalmente son nociones como las de paradigma, sintagma, connotación, actante... El "imperialismo lingüístico", tantas veces denunciado por los defensores de la tradición, era así sobre todo un imperialismo semiológico. Por otra parte, los dominios que más se recorrieron entonces fueron la narratología y la poética (en el estricto sentido de una teoría de la poesía). La narratología, a pesar de algunos préstamos lingüísticos más bien metafóricos (proposición narrativa, modo...), se gestó sin referencia precisa a las ciencias del lenguaje. En cuanto a la poética, mucho tiempo dominada por el problema de la justamente llamada por R. Jakobson "función 
poética", debe poco de su expansión a los progresos en el conocimiento de las lenguas naturales: en ella la poeticidad consiste ante todo en elaborar equivalencias entre unidades de un mismo texto.

El único ámbito de la lingüística que se frecuentó de verdad para la inspección de las obras literarias fue el de los estudios de vocabulario, ya sea desde el punto de vista de la estadística léxica o, de manera más general, de los análisis inspirados por la lexicología estructural: pesquisas distribucionales, campos semánticos, descomposiciones sémicas, etc. La lingüística estructural, que es una lingüística del signo, favorecía ese tipo de investigación. Su alcance era, sin embargo, limitado: en la mayoría de las ocasiones, el vocabulario sujeto al examen no se hallaba integrado en la trama sintáctica o textual, sino inscrito en redes de unidades descontextualizadas, a las que se suponía "representativas" de la obra. La predilección por los estudios de vocabulario se explica igualmente por la facilidad con la que se podían extraer de ellos interpretaciones de orden extratextual, psicológicas o socio-históricas.

Cuando a partir de los años setenta el estructuralismo retrocedió, muchos especialistas en literatura pensaron que la lingüística no estaba en condiciones de proporcionar resultados interesantes en materias literarias, y retomaron estrategias menos técnicas o totalmente ajenas a la tecnicidad. Por su parte, los lingüistas han tendido a focalizarse sobre los hechos de lengua, en detrimento de las perspectivas semiológicas, y han evitado cuidadosamente los corpus literarios, a los que juzgan demasiado alejados del funcionamiento "real" de la lengua.

Con todo, la difusión a partir de los años ochenta de la lingüística textual, de las corrientes pragmáticas y de las teorías de la enunciación lingüística ha abierto la posibilidad de una nueva alianza entre lingüística y literatura.

En un primer nivel, esas nuevas problemáticas han facilitado desarrollar métodos de análisis del texto literario mucho más eficaces que los anteriores, algunos apoyados básicamente en las teorías de la enunciación, y otros que les añaden categorías más pragmáticas, en particular articuladas sobre las nociones de género de discurso y de interacción. Las teorías de la enunciación lingüística, en especial, permiten acceder a hechos de lengua de una gran finura (modalidades, discurso relatado, polifonía, punto de vista, temporalidad, determinación nominal, reformulaciones, conectores argumentativos...), en los que se combinan estrechamente la referencia al mundo y la inscripción del enunciador en su propio discurso. Y la literatura juega intensamente con tales fenómenos, que un comentario estilístico tradicional no posee medios para analizar. Podría decirse que el "grano" del objeto texto ha cambiado, como si se hubiese utilizado para inspeccionarlo un nuevo microscopio, mucho más potente, capaz de modificar nuestra escala de observación. En cuanto a la reflexión sobre la enunciación y los géneros de discurso, esta autoriza a pasar sin solución de continuidad de una lingüística de la frase a una lingüística centrada en los dispositivos de comunicación: el texto se aborda como producto de una práctica interactiva efectuada en el marco de instituciones de palabra que legitiman su enunciación pero que deben a su vez relegitimarse continuamente.

\section{EL ANÁLISIS DEL DISCURSO LITERARIO}

El desarrollo desde los años noventa de aproximaciones fundamentadas en un análisis del discurso literario va más lejos de las citadas aportaciones de las ciencias del lenguaje. Hablar de discurso literario equivale efectivamente a poner en movimiento cierto número de ideas-fuerza (el discurso es una forma de acción, es interactivo, está radicalmente contextualizado, regido por normas, dominado por un interdiscurso, los textos son la huella de actividades de lenguaje, de géneros de discurso inseparables de actividades no verbales, etc.), ideas que transforman las condiciones mismas en las que es posible estudiar la literatura.

Hay obras literarias no porque estas trasciendan toda interacción comunicativa (como se presupone cuando se ve en ellas la expresión de una "visión del mundo"), sino porque gestionan de manera específica, y según modos muy diversos, la interactividad esencial del discurso a través de normas compartidas. Por ejemplo, como cualquier otra actividad de lenguaje, la enunciación literaria no escapa a la órbita del derecho. Palabra y derecho están unidos: de dónde puede venir legítimamente la palabra, a quién pretende dirigirse, bajo qué modalidad, en qué momento, en qué lugar.

Con mayor amplitud, considerar la literatura como discurso es contestar el carácter central de ese punto de origen fijo, sin "comunicación con el exterior", por retomar una célebre fórmula del Contra Sainte-Beuve de Proust, que sería el creador. Uno se aleja así del universo estético abierto por el romanticismo, en el cual el centro de los estudios literarios se encontraba, directa o indirectamente, en la individualidad creado- 
ra. Directamente, cuando se rastreaba su vida; indirectamente, cuando se exploraba el "contexto" de su creación o cuando se leía el texto como expresión de su aludida "visión del mundo". Desde la perspectiva del análisis del discurso, al contrario, para que haya enunciación literaria no basta con poner en contacto un alma con otra: la naturaleza misma de esas "almas" varía con las instituciones de palabra históricamente definidas que las hacen posibles. Al hablar de "discurso literario" se intenta restituir las obras a los espacios donde son producidas, gestionadas, evaluadas. En ellos las condiciones del decir atraviesan lo dicho, y lo dicho remite a sus propias condiciones de enunciación (el estatuto del escritor asociado a su modo de posicionamiento en el campo literario, los roles vinculados a los géneros, la relación con el destinatario construida a través de la obra, los soportes materiales y los modos de circulación de los enunciados, etc.).

La consideración de la comunicación literaria y de su dispositivo de enunciación, lejos de impedir el acceso a lo que sería esencial en la literatura, aparece así como el requisito, el motor y la apuesta de la obra literaria. No cabe concebir la obra como una manipulación de "contenidos" que permitiría "expresar" de manera más o menos indirecta ideologías o mentalidades. En efecto, la idea de que la palabra es una actividad puede parecer banal, y sin embargo modifica los presupuestos que desde hace siglos gobiernan nuestro acercamiento a los textos. Actividades singulares, pero también actividades como otras, las prácticas que dependen del discurso literario no son un "reflejo" más o menos confuso de una realidad independiente: participan en ese mundo que supuestamente "reflejan", el "contenido" de una obra está en realidad atravesado por el reenvío a sus condiciones de enunciación, el texto es la gestión misma de su contexto. Por ejemplo, los trabajos sobre la literatura "galante" del siglo XVII (Denis, 1987; Viala, 1999) traen a un primer plano los ritos de una comunidad de usuarios, a la vez productores, lectores y difusores: sus textos (novelas, madrigales, retratos...) son simultáneamente la condición y el producto de esos ritos, llevados a cabo en un espacio (el salón) que está a la par dentro y fuera de la sociedad, y que es el presupuesto no menos que el único tema de todo ello. Resulta igualmente ilusorio pensar lo que dicen las obras del siglo XIX sin ver cómo inscriben en su enunciación la institución literaria en la que participan: en las novelas de Victor Hugo los marginales Quasimodo el jorobado y Esmeralda la bohemia (Notre-Dame de Paris), o Jean Valjean (Les misérables), son a un tiempo los personajes de una historia y las figuras en las que puede inscribirse el escritor que transmite tal historia; cada una de esas figuras, por su imposible pertenencia a la sociedad, refleja la "paratopía" del escritor romántico (Maingueneau, 1993).

Los escritores producen obras, pero escritores y obras son a su vez producidos por todo un complejo de prácticas. Nos vemos así conducidos a razonar en términos de institución discursiva y a intentar articular:

- Las instituciones de diversos órdenes que confieren sentido a las enunciaciones literarias: la estructura del campo literario, el estatuto del escritor, los géneros de texto, etc.

- El movimiento por el cual se instituye el discurso, a la vez instaurando progresivamente en su enunciado cierto mundo y legitimando el dispositivo de enunciación y el posicionamiento estético en el campo literario que hace posible ese enunciado.

Se podría decir, con mayor precisión, que toda obra posee tres planos indisociables:

- El discurso literario se presenta como una red de aparatos en la que los individuos pueden constituirse en escritores y en públicos, se estabilizan y garantizan los contratos genéricos estimados como literarios (novela, poema, comedia...), intervienen mediadores (editores, libreros, periodistas...), intérpretes y evaluadores legítimos (críticos, profesores...), hay cánones (que pueden adoptar la forma de manuales, de antologías...), etc.

- Se trata también de un campo, de un lugar de confrontación entre posicionamientos estéticos que explotan según su modo propio géneros e idiomas. Tal campo no es una estructura estática, sino un juego de equilibrio inestable en el que se confrontan posicionamientos dominantes y dominados, centrales y periféricos. No se debe sin embargo perder de vista que la idea de un campo artístico verdaderamente autónomo es cosa reciente (siglo XIX), y que está sin duda perdiendo fuerza con el auge actual de las nuevas tecnologías de la comunicación.

- Es por último un archivo, una memora interna de la literatura que, más allá del intertexto en sentido estricto, de la memoria de los textos, incluye también "leyendas", en particular las ligadas a las vidas de los escritores célebres. La actividad creadora hunde sus raíces en esa memoria que, presa en los conflictos del campo literario, se ve sin cesar modificada por cada posicionamiento. Así, en Francia el movimiento de los poetas de la Pléiade del siglo XIX 
rechazó los géneros medievales y, en cambio, promocionó ciertos géneros de la antigüedad griega; al revés, el romanticismo descartó la poesía neoclásica y devolvió su valor a los géneros medievales. Cuando por ejemplo Rimbaud expone su estética en su famosa "Carta del vidente", su exposición se confunde con un recorrido por la historia de la poesía desde la antigüedad. Para el siglo XIX Rimbaud brinda una evaluación de la poesía francesa que toma como criterio su propio posicionamiento, resumido en la necesidad de ser "vidente":

Los primeros románticos fueron videntes sin darse demasiada cuenta de ello; el cultivo de sus almas comenzó con una serie de accidentes: locomotoras abandonadas, pero ardientes, que recorren durante un tiempo los raíles. Lamartine es a veces vidente, pero lo estrangula la forma antigua... Hugo, demasiado testarudo, experimenta visiones en sus últimos volúmenes: Los miserables es un verdadero poema. Tengo a mano Los castigos: Stella da la medida aproximada de la vista de Hugo. Demasiado Belmontet y Lamennais, demasiado Jehová y demasiadas columnas, viejas enormidades acabadas.

Musset es catorce veces más execrable para nosotros, generaciones dolientes y presas de visiones, a las que su pereza de ángel ha insultado [...].

Los segundos románticos son muy videntes: Théophile Gautier, Leconte de Lisle, Théophile de Banville. Pero al ser inspeccionar lo invisible y escuchar lo inaudito asuntos distintos de recuperar el espíritu de las cosas muertas, Baudelaire es el primer vidente, el rey de los poetas, un verdadero Dios. Aun así vivió en un medio demasiado "artístico", y la forma que tantos elogios recibe en él es mezquina -la invención de lo desconocido reclama formas nuevas- (Carta a Paul Demeny, 15 de mayo de 1871).

Extender de esta suerte la noción de discurso literario más allá de las solas obras otorga una legibilidad a corpus ignorados o devaluados, que constituyen de hecho la mayor parte de la producción y que no dependen de la concepción romántica del estilo, aún dominante, como expresión singular de una conciencia creadora. La literatura medieval o galante, la poesía petrarquista, el vaudeville, la comedia-ballet de finales del siglo XVII no son legibles salvo si se evita aprehenderlos a través de categorías anacrónicas, en virtud de las cuales puede decirse que en ellos hay "demasiados clichés", que "carecen de originalidad", etc.

Es la autonomía misma de las obras literarias la que plantea problemas. El discurso literario no es un thesaurus compuesto por algunas obras maestras surgidas de un oscuro "contexto de creación", sino una tupida red de prácticas en espacios muy diversos que deben tomarse en cuenta. La literatura clásica implica a la vez los colegios, los salones y las academias; la literatura del siglo XIX es inseparable de la existencia de periódicos de gran tirada, de revistas literarias, de manuales de literatura nacional, etc.

\section{EL LUGAR DEL ANÁLISIS DEL DISCURSO EN LOS ESTUDIOS LITERARIOS}

Al hablar de "análisis del discurso literario" se sitúa el estudio de la literatura en una esfera que engloba a esta, la del discurso y su análisis. Desde ese momento, dicho estudio ya no se beneficia de un régimen de extraterritorialidad: no se trata de confundir lo "profano" de las ciencias humanas y sociales con lo "sagrado" del arte, como se hace comúnmente, proyectando un universo (las ciencias humanas y sociales) sobre otro (la literatura) que le resultaría extraño, sino de explorar la densa y diversa realidad del discurso. Ello no deja de acarrear consecuencias en el plano institucional.

En tanto la literatura es pensada como un dominio autónomo, no suelen hacerse preguntas sobre el hecho de que su estudio esté reservado a las facultades de Letras tradicionales. A partir del instante en que se la entiende como una manifestación del discurso, tal sentimiento de evidencia se debilita. Cabe incluso preguntarse si el estudio literario puede tenerse por una disciplina, lo cual exigiría un acuerdo previo sobre el significado de este último término. Aun cuando no siempre resulte fácil establecer la diferencia, hay que distinguir entre las disciplinas en el sentido institucional, aquellas que son reconocidas por las prácticas escolares, y las disciplinas que estructuran la investigación. Cada una de ellas posee su propia legitimidad. Por ejemplo, la geografía dispone desde hace mucho tiempo de un sólido anclaje institucional en la enseñanza secundaria y universitaria, pero desde un punto de vista epistemológico su estatuto no está claro. El alumno que cursa geografía puede interesarse tanto por las nubes y los vientos como por las importaciones y exportaciones de ordenadores, por las rocas sedimentarias o por los volcanes, por las variaciones de la demografía, por la urbanización, etc. Para introducir una coherencia mínima de conjunto, los geógrafos afirman que su objetivo es insertar la actividad humana en un paisaje. Ahora bien, esa solución tiene más fuerza retórica que evidencia epistemológica. Cuando un geógrafo hace de verdad investigación, se encuentra espontáneamente sometido a las normas de la so- 
ciología urbana, de la cartografía, de la demografía, de la economía, de la geología, de la meteorología, de la vulcanología, etc.

Hay, en cambio, otro modo de agrupamiento de los investigadores, fundado no sobre la pertenencia a una misma disciplina, de investigación o institucional, sino sobre el hecho de compartir un mismo dominio empírico, un mismo "territorio": la nutrición, el discurso administrativo, los accidentes de trabajo, Internet, etc. De naturaleza pluridisciplinar, tales agrupamientos están ligados de manera más o menos directa a una demanda social. Por lo general asocian investigadores de distintas disciplinas, quienes por lo demás no necesariamente comparten los mismos presupuestos teóricos.

¿Qué sucede entonces con el estudio de la literatura? Como se habrá advertido, nos hemos visto obligados a usar una expresión ("el estudio de la literatura") que no es una etiqueta reconocida. La de "crítica literaria", en boga durante los años sesenta, ha sufrido una marginalización y se la ha reenviado hacia el periodismo; "teoría literaria" parece demasiado restrictiva; "ciencia de la literatura" irrita a muchos especialistas, incluso usada en plural ("ciencias de la literatura"). A nuestro juicio, esta dificultad de orden terminológico es sintomática.

No cabe duda de que la literatura es una disciplina institucional. Pero ¿es una disciplina definida por un interés epistemológico específico, o únicamente una asociación de investigadores de diversas disciplinas que comparten un mismo "territorio", en este caso la producción que se reconoce como literaria? Me parece que es la segunda opción la que se corresponde con la realidad. Aun así, el objeto mismo de los estudios literarios resulta profundamente incierto. La incertidumbre afecta, de entrada, al tipo de textos que deben tomarse en consideración: ¿obras verdaderas o subliteratura?, ¿antiguas o contemporáneas?, ¿nacionales o europeas?... La incertidumbre alcanza también a la extensión de ese dominio: ¿hay que incluir en él solo los textos, o debe llegarse hasta la financiación de los teatros, las técnicas de fabricación de los libros, el estatuto jurídico de los escritores, las prácticas sociales ligadas a la literatura (desde las visitas a las casas de los escritores hasta los reportajes de revistas, pasando por la enseñanza primaria y secundaria, las críticas periodísticas, las imágenes que circulan en la cultura de masas, los premios, las bibliotecas, las actividades de ocio, las adaptaciones de obras en el cine o en la televisión, las traducciones, etc.)? En otros términos, ¿se va a tomar en cuenta el hecho literario en toda su complejidad? ¿O solamente las obras? ¿En- tre ellas, únicamente un thesaurus de obras prestigiosas? Semejante incertidumbre corre pareja con otra concerniente a la finalidad de esos estudios: ¿se trata de interpretar algunas grandes obras?, ¿de practicar la historia cultural?, ¿de analizar los procesos creativos?... Si el verdadero objeto del estudio de la literatura, el que la justifica, es la interpretación de un thesaurus de grandes obras, el analista ha de alejarse de consideraciones socio-históricas o psicológicas que se juzgan ajenas a lo esencial: la relación hermenéutica.

Hay que comprender que el estudioso de literatura se encuentra atrapado en una situación muy delicada. Para ser legítimo en la institución académica, debe reivindicar las normas dominantes en materia de investigación, las normas de las ciencias humanas y sociales; no obstante, para fundar su autonomía necesita rechazar que esas mismas ciencias humanas y sociales tengan derecho a ocuparse de su objeto. Ciertamente la mayoría de los especialistas de literatura están oficialmente organizados en "equipos", incluso en ocasiones en "laboratorios", pero la causa en cuyo nombre se reúnen, la literatura, implica la afirmación de un irredentismo que funda la legitimidad de su disciplina. El miedo a ser anexionados por una potencia exterior une con fuerza a los miembros de la comunidad. Así se ha visto, en las últimas décadas, a los "literatos" rechazar con éxito diversos asaltos, algunos realmente amenazadores (como el de la semiótica en los años sesenta y setenta), otros claramente menos (como la sociología del campo literario de P. Bourdieu).

En esas condiciones, el estudioso de literatura tradicional se siente impelido a desplegar modalidades de enunciación ambiguas, de suerte que confiera a sus palabras algunos atributos de las ciencias humanas y sociales sin por ello dejar de repudiar los presupuestos de estas. Su discurso se vuelve, según las modas, narratológico, lingüístico, sociológico, psicoanalítico, etc., si bien el estudioso de literatura no se somete realmente a las constricciones de dichas disciplinas. El empleo de un término como lectura resulta a este respecto muy significativo: muchos prefieren decir que no practican la sociología de la literatura, sino que efectúan una "lectura sociológica" de las obras. Formulación que presenta la ventaja de invocar las garantías de la sociología sin por ello dejar de preservar el exceso que legitima la relación hermenéutica: no se trata más que de una lectura entre otras de una obra que, de todas maneras, se antoja inagotable.

Es la anterior una posición muy delicada, que hace pensar en el estudio de la religión, dividido entre los departamentos de teología, por una parte, y los de his- 
toria de las religiones o de antropología religiosa, por otra. Los dos tipos de departamentos se distinguen en un punto clave: la teología es asunto de creyentes y se dirige a creyentes, lo cual no sucede con una historia de las religiones o con una antropología religiosa, que se inscriben en la órbita de las ciencias humanas y sociales. Sin embargo, al igual que en los departamentos de literatura, la enseñanza dispensada en los de teología no puede reducirse a un comentario personal de los textos autorizados, pues pretende apoyarse sobre la arqueología, la codicología, la historia, etc., aunque asignándoles un papel subalterno: para la teología, la verdad propiamente religiosa es de otro orden y, como en literatura, no sería imaginable comentar un texto cualquiera, sino solamente las obras verdaderas, el Thesaurus que funda la comunidad de los hermeneutas, un patrimonio del que se es heredero y responsable.

Se da con todo una diferencia, y no desdeñable, entre los departamentos de teología y los de literatura. La teología debe asumir su estatuto fundamentalmente hermenéutico y afirmar con fuerza la soberanía del "sentido espiritual". En cuanto tal, el teólogo no puede llamarse a sí mismo verdadero "investigador" sin dejar de actuar como teólogo para pasar a hacerlo como filólogo, sociólogo, etc. Por el contrario, la posición institucional del especialista en literatura lo obliga a no permitir que se vea demasiado a las claras aquello que hace su proceder irreductible a los de las ciencias humanas y sociales.

Son entonces comprensibles las reticencias de numerosos especialistas literarios ante el análisis del discurso. Este último se les presenta como una empresa nacida de las ciencias sociales cuyo efecto es devolver hacia la comunicación ordinaria aquello que, por derecho, supera toda ordinariez y toda comunicación:

No es posible tratar del discurso literario transponiendo sin más las nociones elaboradas para otros discursos sociales: hace falta una poética (Delas, 2003, p. 343).

Puede oponerse el discurso a la obra. La obra no es un discurso entre otros, es un acontecimiento de escritura y de lectura y una configuración estética [...] Desde esta perspectiva, el análisis del discurso y el del estilo no tienen los mismos propósitos ni tratan de los mismos objetos (Herschberg Pierrot, 2003, p. 338).

La división que así se defiende entre la "poética" y el análisis del discurso legitima un cierto reparto de las tareas en el universo académico: las facultades de Letras tendrían a su cargo las obras verdaderas, y las ciencias humanas y sociales, por propensión natural, los "discursos sociales". Hasta los años sesenta del siglo XX perduró tal distribución tácita: las facultades de Letras analizaban los textos prestigiosos, prestando particular atención al "estilo"; los departamentos de ciencias humanas o sociales, por su parte, abordaban los textos de escasa reputación, los "documentos" indignos de un tratamiento estilístico, que solo eran examinados debido a que facilitaban acceder a las realidades extralingüísticas.

Paradójicamente, las citadas reticencias de los estudiosos de literatura han encontrado cierto refuerzo en los analistas del discurso, quienes evitaban cuidadosamente los textos prestigiosos porque integrar el estudio de la literatura en la disciplina les hubiera obligado a repensar cierto número de sus presupuestos y de sus métodos. En cambio, la estilística sí incorporaba sin vacilaciones algunos instrumentos tomados en préstamo a las corrientes enunciativas y pragmáticas, pero como lo hacía sin poner en cuestión sus gestos esenciales y los distingos institucionales que implicaban, se veía reforzada la descrita repartición excluyente del trabajo.

Ahora bien, con el tiempo, ya entrados los noventa, el desarrollo del análisis del discurso ha tenido como efecto transformar la mirada sobre esos "documentos" secundarios, que han pasado a recibir una atención comparable a la de los textos estudiados en las facultades de Letras, aunque dentro de un marco teórico y metodológico muy diferente. Tan diferente, de hecho, que para el analista del discurso la antítesis entre los textos literarios y los documentos, entre las obras y los discursos sociales, ha perdido toda su pertinencia: el problema ya no reside en oponer obras y discursos, como si las obras no fueran también a su manera discursos "sociales", sino en levantar acta de la diversidad de los discursos en una sociedad dada.

P. Bourdieu no cejó en denunciar la relación "ilusoria" e interesada que mantendrían los especialistas de literatura con las obras, contraponiéndole el "verdadero" saber del sociólogo, capaz de objetivar su propia práctica. El problema es que, a fuerza de querer disipar esta relación relación ilusoria, se acaba recusando incluso el estatuto de la literatura en la sociedad. Si cabe reprochar algo a los estudiosos tradicionales de literatura es el pretender acumular los privilegios del hombre de ciencia y los del hermeneuta, pero no el acogerse a un marco hermenéutico. El universitario de letras debe legitimarse como investigador; ahora bien, ha recibido asimismo el mandato, por parte de la sociedad, de contribuir a la gestión de un patrimonio, de 
garantizar la memoria y los valores colectivos. Lo quiera o no, forma parte de la vida cultural y de la enseñanza. De nada sirve entonces imaginar que, por medio de una conversión súbita, los estudiosos de literatura se pasan al campo de las ciencias humanas y sociales. $\mathrm{Si}$ la literatura como disciplina universitaria ha rechazado constantemente hacerlo, y ya desde finales del siglo XIX (por ejemplo, inventando una "historia literaria" que no es ni historia, ni sociología, ni psicología...), es porque sus especialistas se juegan en ello su estatuto y su identidad, y los de la misma literatura en la sociedad. El marco hermenéutico dentro del cual se inscribe el estudio de la literatura es una dimensión constitutiva del hecho literario, que debe ser pensada como tal. Y esto exige intentar comprender a la vez la necesidad y los límites de ese extraño e imposible saber que es el estudio de la literatura, en cuyo ámbito los "investigadores" y las "disciplinas" han de llevar comillas.

El analista del discurso se ve así obligado a aceptar la escisión de los estudios literarios en dos paradigmas: uno que depende de las ciencias humanas y sociales, y otro de una hermenéutica de las obras. Su divergencia puede ser puesta de relieve a través de algunos puntos significativos (Tabla 1).

La dedicación privilegiada de la gran mayoría de los especialistas de literatura a un autor o a un siglo, más que a una teoría o a un método como en las ciencias sociales, proviene del hecho de que la actividad del estudioso literario se alimenta de una forma de amor. Cabe pensar aquí en el distingo entre gramático y lingüista. Si el "gramático" es el que se entrega al estudio de una única lengua, la suya, objeto de toda su pasión, su empresa se confunde con el desvelamiento de las bellezas de esta. Del mismo modo, el genuino estudioso de literatura establece un vínculo esencial con su parte del thesaurus, aquella que ama, mientras que el objeto del lingüista es el lenguaje, y no tal o cual lengua, siendo el objeto del análisis del discurso el discurso en toda su diversidad.

Los defensores de las aproximaciones discursivas a la literatura no pueden sin embargo ignorar que llevan a cabo una empresa de segundo nivel. En efecto, las aproximaciones dependientes del paradigma hermenéutico se sitúan como una prolongación de la relación espontánea con las obras, la relación que prevalece en la "vida cultural"; en cambio, las discursivas son ascéticas, y van contra las representaciones y las prácticas ingenuas de los usuarios de literatura.

La irrupción de estas problemáticas de orden discursivo es el resultado de una reconfiguración general del saber, y no solamente de una rectificación local de la frontera en el seno de las facultades de Letras. Todo el asunto se cifra en sopesar si el estudio de los fenómenos que hoy se agrupan comúnmente bajo la etiqueta de "literatura" ha de ser exclusivamente literario, condenando todas las demás posibilidades a verse tildadas

Tabla 1. Paradigma hermenéutico versus Paradigma discursivo

\begin{tabular}{|l|l|}
\hline \multicolumn{1}{|c|}{ PARADIGMA HERMENÉUTICO } & \multicolumn{1}{|c|}{ PARADIGMA DISCURSIVO } \\
\hline OBJETO \\
\hline Análisis restringido a las obras. & $\begin{array}{l}\text { Corpus definido en función del objetivo de la investigación: } \\
\text { puede incluir paraliteratura, géneros conexos (comentarios, } \\
\text { manuales, etc.) y textos que emanan de otros muchos tipos } \\
\text { de discurso (político, jurídico, etc.). }\end{array}$ \\
\hline \multicolumn{2}{|c|}{ SINGULARIDAD } \\
\hline $\begin{array}{l}\text { Focalización sobre la unicidad de cada obra y de su } \\
\text { comentarista. }\end{array}$ & $\begin{array}{l}\text { Focalización sobre las invariantes del discurso literario, y } \\
\text { estudio de las condiciones de posibilidad de la unicidad de } \\
\text { las obras. }\end{array}$ \\
\hline $\begin{array}{l}\text { Producción de nuevas interpretaciones sobre un fondo de } \\
\text { inagotabilidad del sentido de las obras. }\end{array}$ & $\begin{array}{l}\text { Estudio de las condiciones de la interpretabilidad de los } \\
\text { textos en un momento y en un lugar dados. }\end{array}$ \\
\hline \multicolumn{2}{|c|}{ COMUNIDADES } \\
\hline $\begin{array}{l}\text { Especialistas distribuidos por lo general en comunidades } \\
\text { definidas en función del interés por un autor o un período. }\end{array}$ & $\begin{array}{l}\text { Comunidades de especialistas que comparten cierto } \\
\text { número de conceptos y de métodos. }\end{array}$ \\
\hline
\end{tabular}


de "reduccionistas". Para el análisis del discurso está claro que no, y que el estudioso tradicional de literatura debe renunciar a apropiarse el hecho literario, del mismo modo en que el teólogo se ha visto obligado a renunciar a apropiarse el hecho religioso.

\section{AGRADECIMIENTOS}

Original en francés traducido por Manuel González de Ávila.

\section{NOTAS}

1. Estas pocas páginas son extremadamente alusivas. Para una presentación más circunstanciada, véase Maingueneau (2004).

\section{BIBLIOGRAFÍA}

Delas, D. (2003). Stylistique, poétique et analyse du discours. En: Amossy, R. y Maingueneau, D. (eds.). L'Analyse du discours dans les études littéraires. Toulouse: Presses Universitaires du Mirail, pp. 341-348.

Denis, D. (1987). La Muse galante. Poétique de la conversation dans l'œuvre de Madeleine de Scudéry. Paris: Honoré Champion.

Herschberg Pierrot, A. (2003). La question du style. En Amossy, R. et Maingueneau, D. (eds.). L'Analyse du discours dans les études littéraires. Toulouse: Presses Universitaires du Mirail, pp. 333-340.

Maingueneau, D. (1993). Le Contexte de l'œuvre littéraire. Paris: Dunod.

Maingueneau, D. (2004). Le Discours littéraire. Paratopie et scène d'énonciation. Paris: Armand Colin.

Proust, M. (1954). Contre Sainte-Beuve. Paris: Gallimard.

Proust, M. (1989). À la recherche du temps perdu (tome IV). Paris: Gallimard.
Spitzer, L. (1948). Stylistics and literary history. Princeton: Princeton University Press.

Viala, A. (1999). L'éloquence galante, une problématique? En Amossy, R. (ed.). Images de soi dans le discours. La construction de l'ethos. Lausanne: Delachaux et Niestlé, pp. 172-191. 